\title{
A EMPATIA NA PRODUÇÃO DE MATERIAIS DIDÁTICOS: REFLEXÕES SOBRE ARTEFATOS BILÍNGUES.
}

\author{
Claudia Pimentel ${ }^{\mathrm{i}}$ \\ Keissy Sibelly Morais Limite ${ }^{\text {ii }}$
}

\begin{abstract}
Resumo: O objetivo desse artigo é refletir sobre a produção de materiais didáticos para a Educação Infantil de surdos. A metodologia proposta se baseia na análise de materiais construídos por professoras, procurando perceber como e se favorecem a ampliação de sentidos, na medida em que dialogam com contextos mais amplos, como livros, cantigas e narrativas. A perspectiva teórica contempla a concepção de linguagem bakhtiniana, que entende que a enunciação organiza o pensamento. A organização estética dos materiais revela princípios éticos e epistemológicos. Percebemos que a produção de artefatos junto com as crianças, de maneira empática, produziu efeitos significativos no relacionamento interpessoal, aprimorou a comunicação e colaborou para aprendizagens significativas.
\end{abstract}

Palavras-chave: Educação Infantil; Empatia; Artefatos bilíngues; Educação de surdos.

\section{EMPATHY IN THE PRODUCTION OF TEACHING MATERIALS: REFLECTIONS ON BILINGUAL ARTIFACTS.}

\begin{abstract}
The purpose of this article is to reflect on the production of teaching materials for the education of deaf children. The proposed methodology is based on the analysis of materials constructed by teachers, seeking to understand how and how they favor the expansion of meanings, as they dialogue with broader contexts, such as books, songs and narratives. The theoretical perspective contemplates the concept of Bakhtinian language, which understands that enunciation organizes thought. The aesthetic organization of the materials reveals ethical and epistemological principles. We realized that the production of artifacts together with children, in an empathic way, produced significant effects on interpersonal relationships, improved communication and collaborated for meaningful learning.
\end{abstract}

Keywords: Early Childhood Education; Empathy; Bilingual artifacts; Deaf education.

\section{Introdução}

O objetivo deste artigo é refletir sobre a produção de materiais didáticos para a Educação Infantil de surdos. A Educação Infantil é considerada a primeira etapa da Educação Básica, conforme definições das Diretrizes Curriculares Nacionais para a Educação Infantil DCNEI (BRASIL, 2010), reafirmadas no documento da Base Nacional Comum Curricular BNCC (BRASIL, 2017). O eixo que sustenta a argumentação é a afetividade presente na 


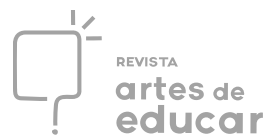

construção de uma pedagogia da infância que pense na inclusão de crianças surdas pela centralidade da língua de sinais e também por estratégias e saberes didáticos, num possível currículo da Educação Infantil baseado na experiência.

A metodologia proposta se baseia na análise de alguns materiais construídos por professoras, procurando perceber como e se favorecem a ampliação da construção de sentidos, na medida em que dialogam com contextos mais amplos, como livros, cantigas e narrativas. A perspectiva teórica contempla a concepção de linguagem bakhtiniana, que entende que a enunciação organiza o pensamento.

Olhar para as estratégias e os saberes didáticos implica considerar a organização estética dos materiais que revela princípios éticos e epistemológicos. O princípio da empatia na produção de artefatos pedagógicos ganha destaque, pois implica na escolha e produção de materiais que se dirijam à criança, ampliando relações, afetos, significados. No caso das crianças surdas, percebemos que a relevância está em considerá-las como sujeitos ativos e produtoras de sentidos.

Segundo as Diretrizes Curriculares Nacionais para a Educação Infantil (BRASIL, 2010), as crianças aprendem na experiência. Essa concepção é reafirmada na Base Nacional Comum Curricular (BNCC), na sua terceira versão, publicada em 2017. Na BNCC, a noção de experiência se baseia nos direitos de aprendizagem das crianças que reforçam os princípios da criança ativa que interage, brinca e participa. O currículo da Educação Infantil se estrutura em propostas que consideram os saberes das crianças na relação com os saberes socialmente valorizados, sendo definido como:

Conjunto de práticas que buscam articular as experiências e os saberes das crianças com os conhecimentos que fazem parte do patrimônio cultural, artístico, ambiental, científico e tecnológico, de modo a promover o desenvolvimento integral de crianças de 0 a 5 anos de idade. (BRASIL, 2017, p. 12)

Este documento propõe objetivos de aprendizagem e de desenvolvimento que contemplam três grupos de faixas etárias: bebês, de zero a um ano e 6 meses; crianças bem pequenas, de um ano e sete meses a três anos e onze meses, e crianças pequenas, de quatro a cinco anos e onze meses.

Percebe-se, nesses dois documentos do Ministério da Educação (MEC), um embasamento nas teorias do desenvolvimento que compreendem a importância da criança interagir de forma lúdica, curiosa e afetiva com seus pares, o entorno e o conhecimento, de forma a compreender-se e conhecer o mundo. Entende-se que o currículo da Educação 
Infantil não tem como objetivo a transmissão de conceitos abstratos. $O$ professor deve ser capaz de proporcionar situações de aprendizagem que favoreçam experiências concretas das crianças:

Considerando que, na Educação Infantil, as aprendizagens e o desenvolvimento das crianças têm como eixos estruturantes as interações e as brincadeiras, assegurando-lhes os direitos de conviver, brincar, participar, explorar, expressar-se e conhecer-se, a organização curricular da Educação Infantil na BNCC está estruturada em cinco campos de experiências, no âmbito dos quais são definidos os objetivos de aprendizagem e desenvolvimento. Os campos de experiência constituem um arranjo curricular que acolhe as situações e as experiências concretas da vida cotidiana das crianças e seus saberes, entrelaçando-os aos conhecimentos que fazem parte de patrimônio cultural. (BRASIL, 2017, p. 36)

Esse estudo pretende analisar estratégias e recursos pedagógicos pertinentes à proposta curricular da Educação Infantil e suas possíveis relações com a educação de surdos. Justificase essa intenção diante da proposta do novo edital do Programa Nacional do Livro Didático (PNLD 2022 ${ }^{\mathrm{iii}}$ ), que propõe em seu objetivo número 1 a aquisição de "obras didáticas destinadas aos estudantes, professores e gestores da educação infantil". A própria redação do objetivo do edital desconsidera a especificidade da infância como tempo das crianças de conhecerem a si e ao mundo ao seu redor, ao considerá-las “estudantes".

Compreende-se, neste artigo, que o princípio da empatia na produção dos materiais didáticos pressupõe que a criança possa reconhecer a si e a seus professores como autores na estética desses materiais, em seus acabamentos, na sua materialidade. Questiona-se como esse princípio pode estar presente em materiais comprados em larga escala e para regiões tão diferentes que compõem o Brasil. No entanto, não é intenção desse estudo analisar o PNLD, mas sim subsidiar novas propostas didáticas a partir da análise de alguns artefatos produzidos para a educação bilíngue de surdos.

A teoria da enunciação de Bakhtin (2004) aponta que "o pensamento não existe fora da sua expressão potencial e consequentemente fora de sua expressão da orientação social dessa expressão e o próprio pensamento" (p. 117). A expressão do pensamento se dá na interrelação social. $\mathrm{O}$ ato da comunicação pressupõe um diálogo entre sujeitos, nem sempre presentes externamente, ao considerarmos também um "auditório social" com diferentes apreciações, opiniões e impressões, interno ao sujeito da enunciação. A enunciação organiza o pensamento a partir dessas diferentes "vozes", sendo, portanto, sempre social. A perspectiva bakhtiniana nos ajuda a pensar sobre a produção de materiais didáticos pela importância de considerar a quem se destinam, onde circulam e quais são seus propósitos, sendo o foco desse 
estudo os objetos em si, sua materialidade, sua estética e os contextos de circulação pretendidos. Como produto, os materiais dão acabamento ao pensamento, revelam e organizam opções, escolhas, valores, uma estética.

O convite à visualidade se radicaliza no campo da educação de surdos. Esse campo é um auditório social com múltiplas determinações, sendo o uso da língua de sinais (Libras) uma força cada vez mais visível e legitimada em leis e decretos (como o Decreto 10.502 de 30 de setembro de $2020^{\text {iv }}$ ). Não podemos desconsiderar como os materiais são construídos, a quem se destinam e quais princípios podem ser destacados como norteadores para a produção de outros artefatos.

Entendemos que a visualidade está presente nos espaços e nos objetos e que a infância é o tempo da experiência e não de aprendizagens baseadas apenas em conceitos abstratos. Aquilo que cerca as crianças e que está diante dos seus olhos ganha uma importância ainda maior quando se pensa a educação de surdos:

As técnicas, recursos e perspectivas utilizados nos aspectos da visualidade na educação de Surdos, estão relacionados com o uso da "visão", em vez da "audição", sendo que a imagem na "apreensão do estímulo visual" e perspectiva emergem de acordo com forças bidimensionais e tridimensionais. Esses processos exigem uma nova forma de pensar o nível perceptivo e o processamento visual daquilo que rodeia o sujeito Surdo e qual seu olhar sobre o mundo no processo de ensinar e aprender. (CAMPELLO, 2008, p. 136)

Taveira (2014) e Taveira \& Rosado (2017) categorizam artefatos culturais produzidos por instrutores e professores surdos ou bilíngues para o ensino de crianças surdas. Entendem que esses sujeitos planejam suas aulas, usando "uma espécie de pré-visualização" (2017, p. 31). Como designers, utilizam diferentes técnicas, relacionando palavras, imagens, formas. A elaboração desses artefatos (fotografias compondo imagens representativas, vídeos, computação gráfica, linguagens híbridas) pressupõe uma estética, às vezes intuitiva, mas que acaba por sugerir uma gramática visual.

Essa visualidade pretendida na educação de surdos, que implica no uso da língua de sinais (gesto-visual), nos convida a analisar e produzir materiais didáticos. Esse convite amplia nosso olhar para alguns materiais já tradicionais da Educação Infantil, como livros, bonecas e brinquedos, passa por objetos bilíngues que abrigam a Língua Portuguesa escrita, fotografias com registros de sinais (relacionados ao letramento/alfabetização) e não deixa de fora as possibilidades contemporâneas relacionadas às mídias móveis (celulares, tabletes) e suas possibilidades de registros em vídeos. 
$\mathrm{O}$ uso de linguagem visual e das modalidades da forma visual e das combinações, dos hibridismos que denotam as características da visualidade, é uma questão de sobrevivência dos surdos, dos seus costumes e do compartilhamento de práticas desses sujeitos, em comunidade. (TAVEIRA, 2014, p.77)

A esses temas, sobre a qualidade visual dos materiais produzidos para educação de surdos, soma-se a concepção de criança presente nas Diretrizes Curriculares Nacionais para a Educação Infantil (BRASIL, 2010):

Sujeito histórico e de direitos que, nas interações, relações e práticas cotidianas que vivencia, constrói sua identidade pessoal e coletiva, brinca, imagina, fantasia, deseja, aprende, observa, experimenta, narra, questiona e constrói sentidos sobre a natureza e a sociedade, produzindo cultura. (BRASIL, p. 12, 2010)

A construção dessa visão sobre a criança como sujeito ativo e de direitos é fruto de longa história. A partir das sociedades territorialmente organizadas em Estados-nação, com economia capitalista (dominada pela produção industrial em larga escala de bens para o mercado e pela propriedade privada) e com emergência de novas classes médias e operárias, surge o sentimento de infância como traço distintivo da modernidade. A infância se constitui como um produto de mudanças sociais. Até então, prevalecia o modelo evolucionista para o qual a criança equivalia aos seres primitivos. A epistemologia genética piagetiana traz a noção de construtivismo, ao considerar a criança como sujeito ativo que interpreta, organiza e usa as informações do ambiente, construindo concepções próprias do mundo. O desenvolvimento intelectual não é simplesmente um acúmulo de atividades, mas uma progressão constituída de estágios distintos de habilidade cognitiva que vão do período sensório-motor ao nível das operações formais (BORBA, 2005, p.26).

A mudança de paradigma em relação à infância como tempo de colonização e domesticação para a compreensão de que a infância é momento de produção de conhecimento, de cultura e de interpretações, leva tempo. Além de certo avanço percebido a partir das contribuições de cunho piagetiano, é preciso considerar algumas mudanças no cenário histórico-cultural.

Com a criação da UNICEF $^{v}$ no segundo pós-guerra e a aprovação das Nações Unidas da Convenção sobre os Direitos da Criança, em 1989, a criança passa a ser portadora de direitos de proteção, provisão, liberdades e participação. Pela primeira vez, na retórica oficial, 


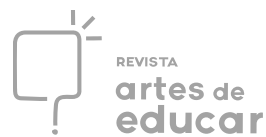

em escala global, aparece uma representação participativa da criança, entendida quase como um parceiro do adulto no contrato social.

A criança, objeto tradicional da psicologia, através do filão das teorias do desenvolvimento, ganha cada vez mais espaço nas teorias da sociologia e nos estudos sobre a infância. Aos parâmetros iniciais organizados em binômios reducionistas como o mestre e o aprendiz, o maduro e o imaturo, acrescenta-se aos poucos a percepção de uma criança ativa, que molda e constitui o adulto, numa relação de aprendizagem, tanto do adulto, quanto da criança.

É para essa criança, ativa e de direitos, que a empatia ganha destaque na construção de materiais didáticos. A impessoalidade de materiais apostilados abre pouco espaço ao diálogo e à produção de sentidos com as crianças pelo distanciamento do seu lugar de produção em relação às realidades locais.

$\mathrm{Na}$ educação de surdos, nas interações com as crianças, o corpo sinalizante ganha importância e a atenção às reações e respostas das crianças também. Tatiana Lebedeff (2007) apresenta, em artigo publicado pela ANPED $^{\text {vi }}$, a proposta de leitura compartilhada ${ }^{\text {vii }}$ da escola americana Gallaudet ${ }^{\text {viii }}$, referência na educação de surdos. Segundo Lebedeff, essa proposta faz parte de formação direcionada a pais e familiares ouvintes de crianças surdas.

A proposta de leitura compartilhada de Gallaudet se baseia em 15 (quinze) princípios, que buscam garantir a compreensão das crianças sobre o que está sendo proporcionado a elas no momento da leitura. Não há obrigação de tradução de todas as palavras em sinais nem de explicação de todos os conceitos de uma vez, pois é importante que se repita a experiência com o mesmo livro sempre que o interesse da criança for percebido, sendo facultado o direito de pular páginas ou abandonar o livro de acordo com o desejo da criança. Ainda que seja possível adaptar a narrativa à capacidade de compreensão da criança, é importante que o adulto se esforce para fazê-la compreender através de explicações paralelas e outros recursos tais como mostrar objetos e proporcionar experimentações. "Para que a história seja mais compreensível para a criança, (...) aos poucos, ao perceber que a criança realmente compreendeu o foco da narrativa, o leitor, lentamente, deverá focalizar mais e mais no texto" (LEBEDEFF, 2007).

Acionar as experiências já vividas pelas crianças é relevante, de forma que se percebe que, na proposta de leitura compartilhada de Gallaudet, a interação adulto-criança é considerada, de fato, uma via de mão dupla. Um dos princípios que explicita a importância da troca dialógica com a criança sugere: "Usar o contato visual para convocar a participação da criança. Olhar a criança ao ler, comunicar-se com o olhar, convocar a Revista Interinstitucional Artes de Educar. Rio de Janeiro, V. 7, N. 1 - pág. 650-669 janeiroabril de 2021: "Pedagogias Vitais: Corpo, Desejo e Educação" DOI: 10.12957/riae.2021.55349 
participação com o olhar que pode ser questionador, exclamativo, entre outros" (LEBEDEFF, 2007).

Apenas imprimir atividades prontas e engessadas da internet não garante a aprendizagem dos alunos, também não atende ao estabelecido nas Diretrizes Curriculares Nacionais para Educação Infantil (2010, p. 18) que tem como objetivo "garantir à criança acesso a processos de apropriação, renovação $e$ articulação de conhecimentos $e$ aprendizagens de diferentes linguagens [...]"

Para efetivação de seus objetivos, as propostas pedagógicas das instituições de Educação Infantil deverão prever condições para o trabalho coletivo e para a organização de materiais, espaços e tempos que assegurem: [...] A indivisibilidade das dimensões expressivomotora, afetiva, cognitiva, linguística, ética, estética e sociocultural da criança; (BRASIL, 2010, p. 19)

Visando o cumprimento desses pressupostos, a criança precisa construir, participar da elaboração de seus materiais, ter oportunidade de ser sujeito de sua aprendizagem, tendo respeitados os seus gostos, opiniões e modos de ver o mundo. Isso acontece quando o docente oportuniza ao aluno o fazer pedagógico, incentiva sua criatividade e fornece subsídios para o seu processo criativo. O professor autor é também um modelo para a criança. Assim como ler para a criança a sensibiliza para a leitura, produzir materiais a incentiva a fazer do seu jeito, sem seguir padrões estereotipados e repetitivos. Reconhecer o professor-autor autoriza a autoria da criança. Tratando-se de crianças surdas, é importante observar as suas peculiaridades linguísticas e culturais. Sabemos que os surdos são visuais, ou seja, seu principal veículo de comunicação são os olhos. Por isso, a atenção do professor quanto às cores, formas e dimensões na criação de materiais para surdos é redobrada. As crianças precisam se reconhecer nos materiais didáticos.

Para melhor explicitar os princípios aqui apresentados, serão analisados alguns materiais. O primeiro material é um tapete construído para contar histórias (Figura 3). Alguns elementos como cenários e personagens foram criados a exemplo das ilustrações presentes nos livros da coleção Histórias da Onça, de Ângela Lago, da Editora Rocco (Figura 2). A proposta era aguçar a atenção da criança para os livros. As interações e a brincadeira propostas na hora da contação das histórias para as crianças tinham como objetivo central sensibilizá-las para a leitura. O apoio na estética proposta no livro (cores, formas, acabamentos) estava a serviço do olhar da criança, sua curiosidade, sua capacidade de observação: 


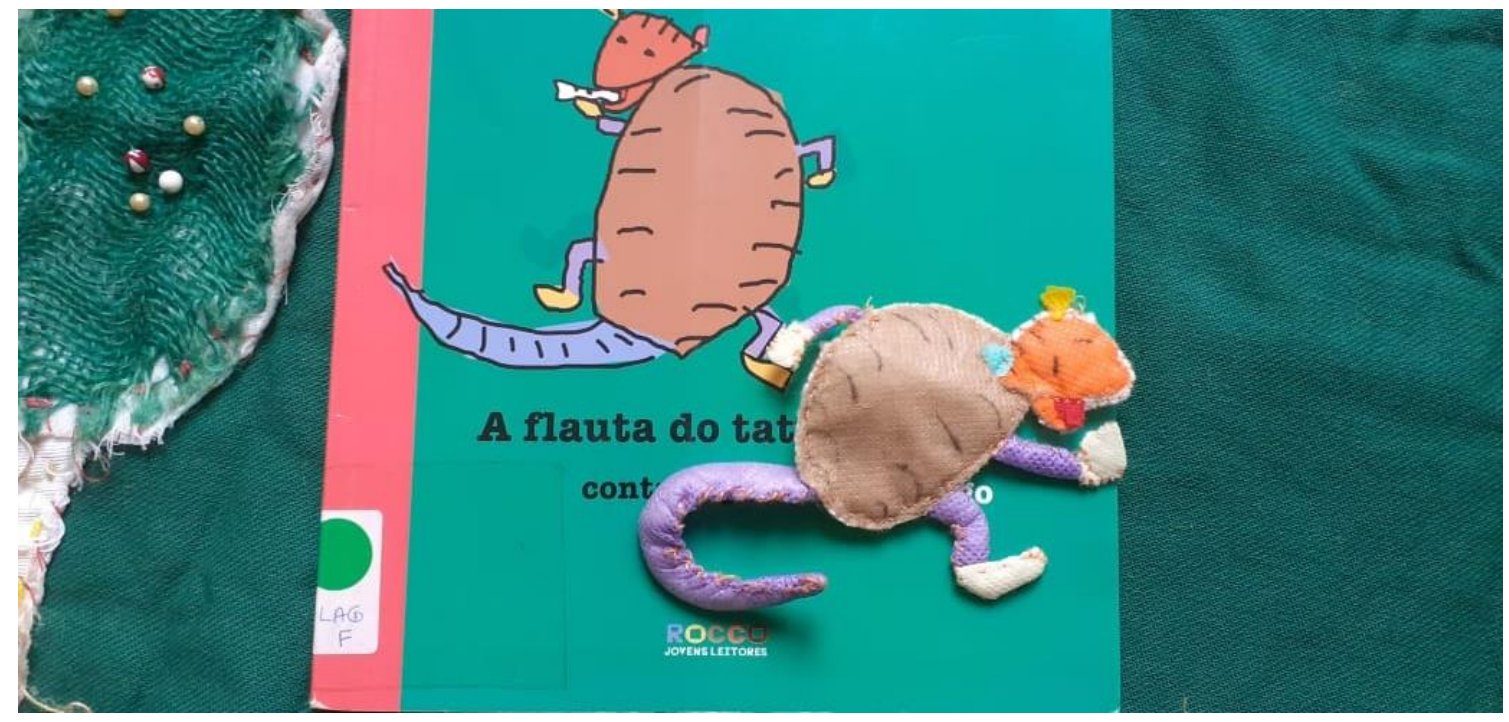

Figura 2: Cenário e bonecos construídos a partir da estética proposta pelo livro de Ângela Lago.

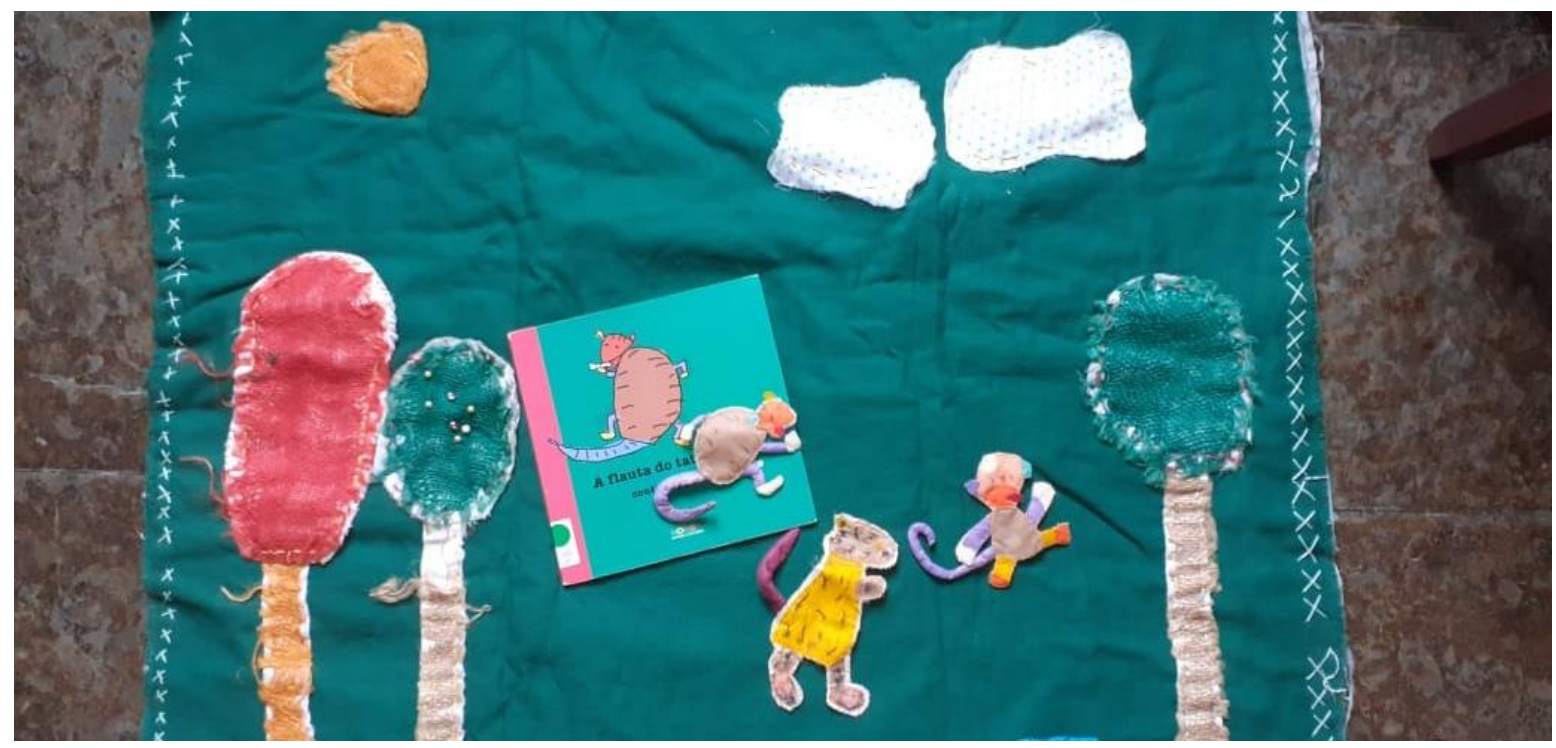

Figura 3: Tapete e bonecos construídos a partir da estética proposta pelo livro de Ângela Lago.

Muitas vezes, o ofício do professor requer habilidades artesanais. A construção de materiais, principalmente quando feita em parceria com as crianças, desperta dimensões autorais, estimulando a construção de objetos pelos sujeitos, o desenvolvimento da autonomia e uma aprendizagem significativa, pela qual o aluno constrói seus próprios sentidos e firma os novos saberes em conhecimentos previamente adquiridos. Ele é o protagonista.

Apresentamos como segundo material um relógio com ponteiros móveis (Figura 6), confeccionado pela professora junto com os alunos. Ela levou para a sala de aula os materiais necessários (Figuras 4 e 5) e com a participação das crianças construíram juntos esse recurso didático para a introdução do conceito de tempo, reconhecendo os números, a importância das horas, para que serve o relógio, o horário das atividades escolares, dentre outras Revista Interinstitucional Artes de Educar. Rio de Janeiro, V. 7, N. 1 - pág. 650-669 janeiroabril de 2021: "Pedagogias Vitais: Corpo, Desejo e Educação" DOI: 10.12957/riae.2021.55349 
possibilidades para este trabalho na Educação Infantil. Foram usados: uma tampa de papelão, tinta de tecido, pincel, números em Libras, algarismos, caixa de leite, clips, fita adesiva.

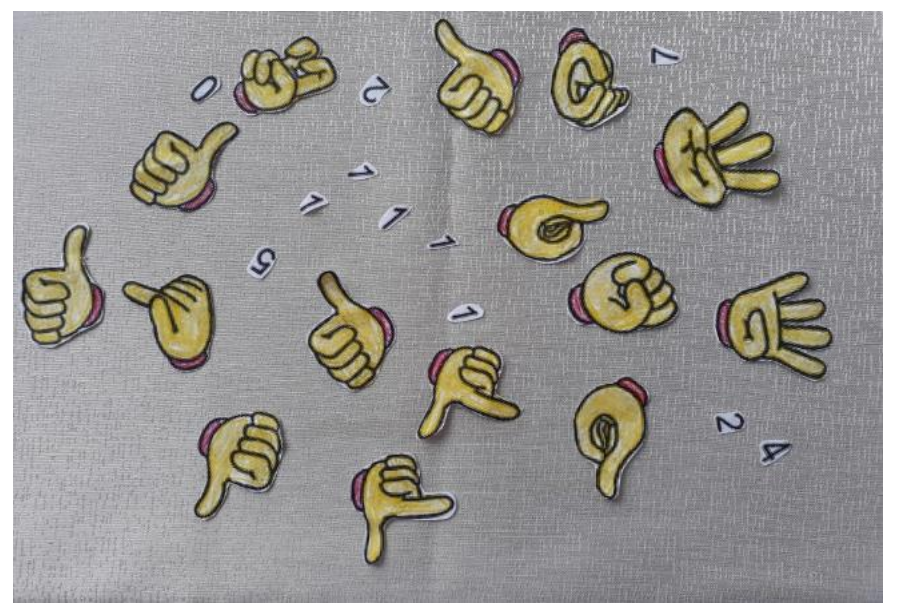

Figura 4: Sinais dos números e algarismos

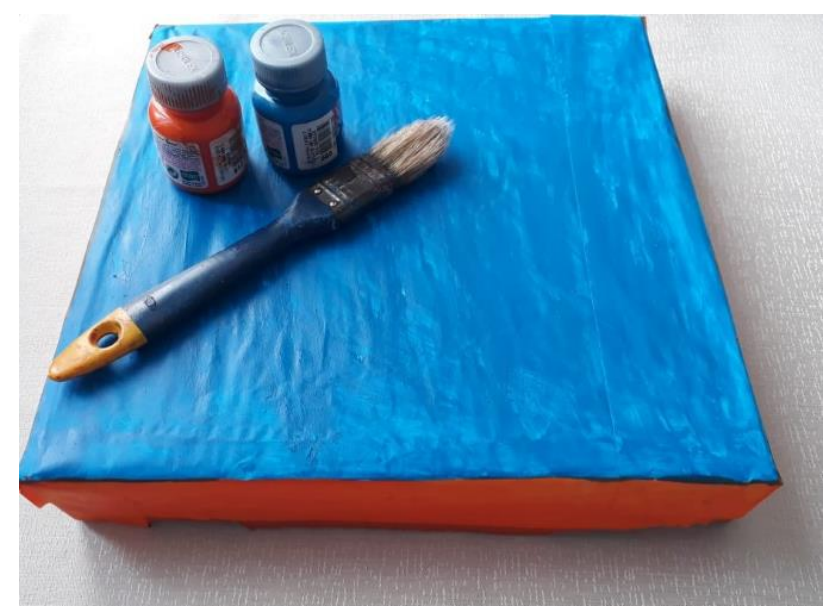

Figura 5: Materiais utilizados

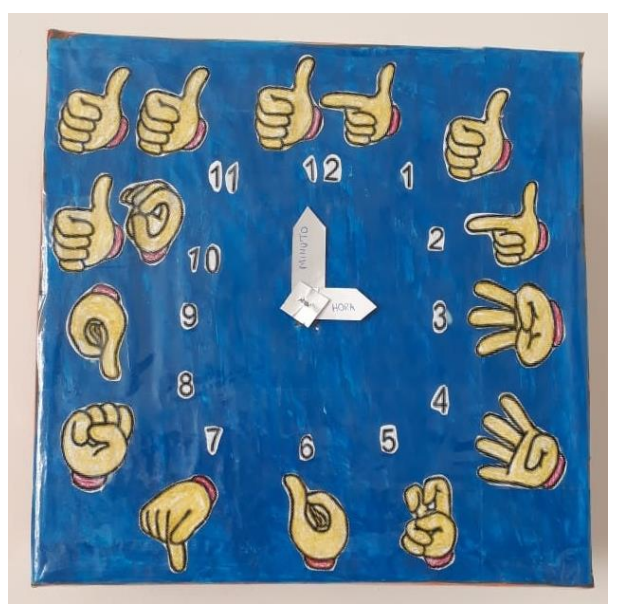

Figura 6: Relógio confeccionado pela professora 
O relógio confeccionado com algarismos e sinais permite a movimentação dos ponteiros. Por ter sido feito junto com as crianças, tem identidade única.

$\mathrm{Na}$ internet encontra-se vários modelos para inspirar a confecção dos materiais por professores, mas há a necessidade de cuidado em observar se a língua de sinais está em evidência, se não há poluição visual, entre outros aspectos relevantes na hora da escolha, evitando excessos de cores, formas mal distribuídas ou qualquer outro empecilho para a visualidade do material ou compreensão clara da mensagem a ser passada. Muitas vezes esses materiais são estereotipados, mas dão algumas pistas para a elaboração de materiais autorais e esteticamente mais personalizados, o que é ideal para gerar empatia.

Analisaremos agora o terceiro material, composto por um conjunto de fantoches de papelão, pensados para a Libração da história $O$ domador de Monstros, da autora Ana Maria Machado, da editora FTD. O termo sugerido "libração" advém da sigla Libras, que significa Língua Brasileira de Sinais, tendo-a como um substantivo próprio, ao adicionarmos o sufixo ÇÃO, ela passa para a classe gramatical dos verbos, tornando-se um verbo de ação, que se refere a ação de contar histórias em Libras, ou seja, Libração.

O livro desta história, escrita em Língua Portuguesa e ilustrada por Suppa, conta com imagens coloridas e um total de 31 páginas. Essa narrativa é considerada como parte da Literatura Ouvinte e, para ser usada com um público surdo, foi necessário inseri-la em uma modalidade da Literatura Surda (MOURÃO, 2016). Escolhemos a modalidade da Tradução que consiste em traduzir o texto para a Libras sem modificar o contexto nem os personagens, mas realizando algumas adaptações.

A narrativa gira em torno do personagem Sérgio, um menino que tinha medo do escuro e que em uma noite começa a olhar o movimento das árvores pela janela do seu quarto e imagina alguns monstros. Sérgio conversa com os monstros pedindo para irem embora, mas como eles sempre se recusam, ele chama um monstro ainda mais feio para assustá-los. No final, o menino acaba achando os monstros engraçados e cai na gargalhada fazendo com que seu medo vá embora. É uma narrativa divertida, que mexe com a imaginação das crianças, com um contexto que muitas se identificam. Originalmente, aparecem oito monstros na história, mas, para os efeitos desta pesquisa, mantivemos as características dos monstros dividindo-as em apenas em três. Ao todo usamos quatro personagens na versão em Libras da história, sendo o Sérgio e mais três monstros.

Os fantoches de pratos de papelão têm os seguintes objetivos: auxiliar no conto da história, chamar a atenção das crianças, servir como recurso visual, despertar a imaginação da plateia, permitir o manuseio dos discentes. Os pratos de papelão foram pintados com tinta de Revista Interinstitucional Artes de Educar. Rio de Janeiro, V. 7, N. 1 - pág. 650-669 janeiroabril de 2021: "Pedagogias Vitais: Corpo, Desejo e Educação" DOI: 10.12957/riae.2021.55349 
tecido, as partes de seus rostos e corpos foram confeccionadas com recortes de papel colorido, colados com cola permanente. Eles representam os personagens da narrativa e possuem os mesmos atributos físicos, para que as crianças possam fazer relações e inferências. Observe as fotos das ilustrações do livro (Figuras 7 e 8) e os personagens feitos pela professora (Figura 9). Os monstros reproduzidos têm as mesmas quantidades de olhos, boca, nariz, chifres, línguas dos monstros da narrativa.

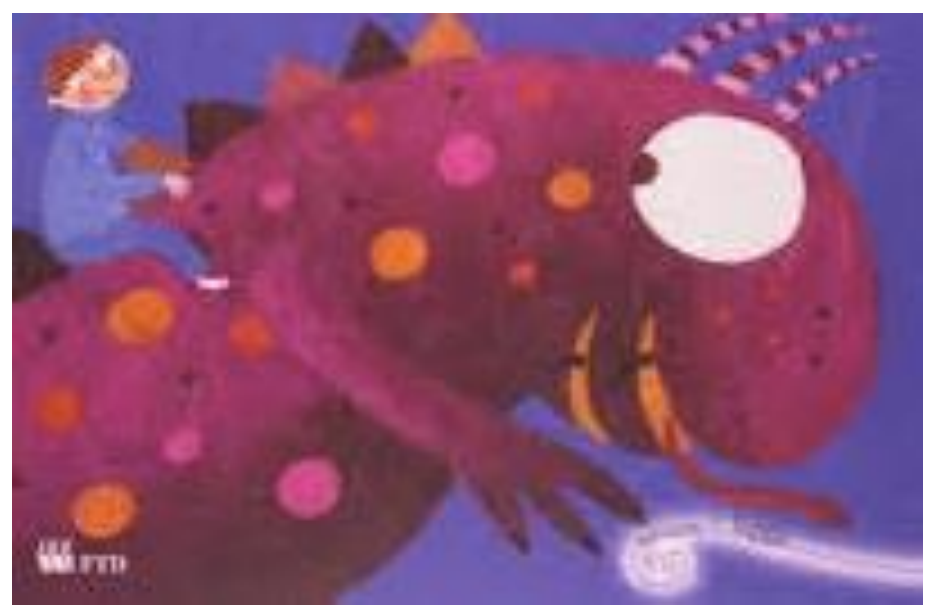

Figura 7: Capa do livro

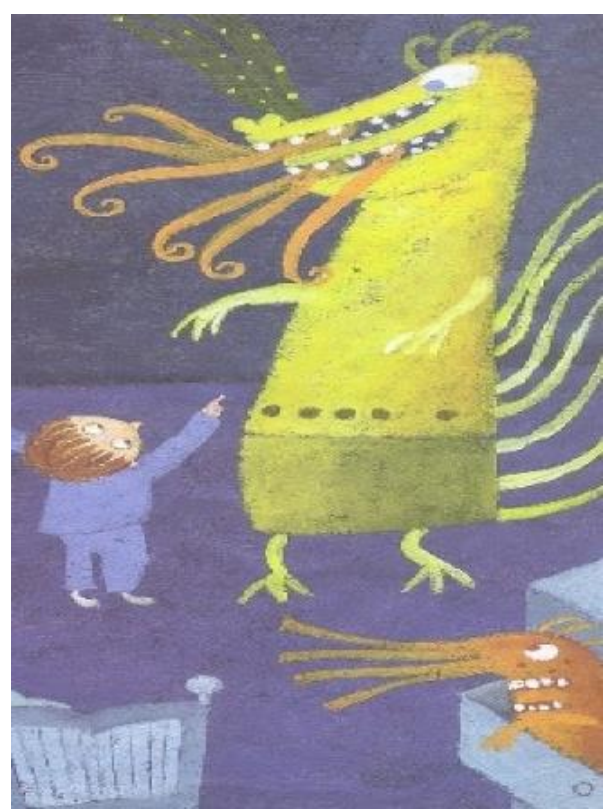

Figura 8: Imagem do livro página 22 


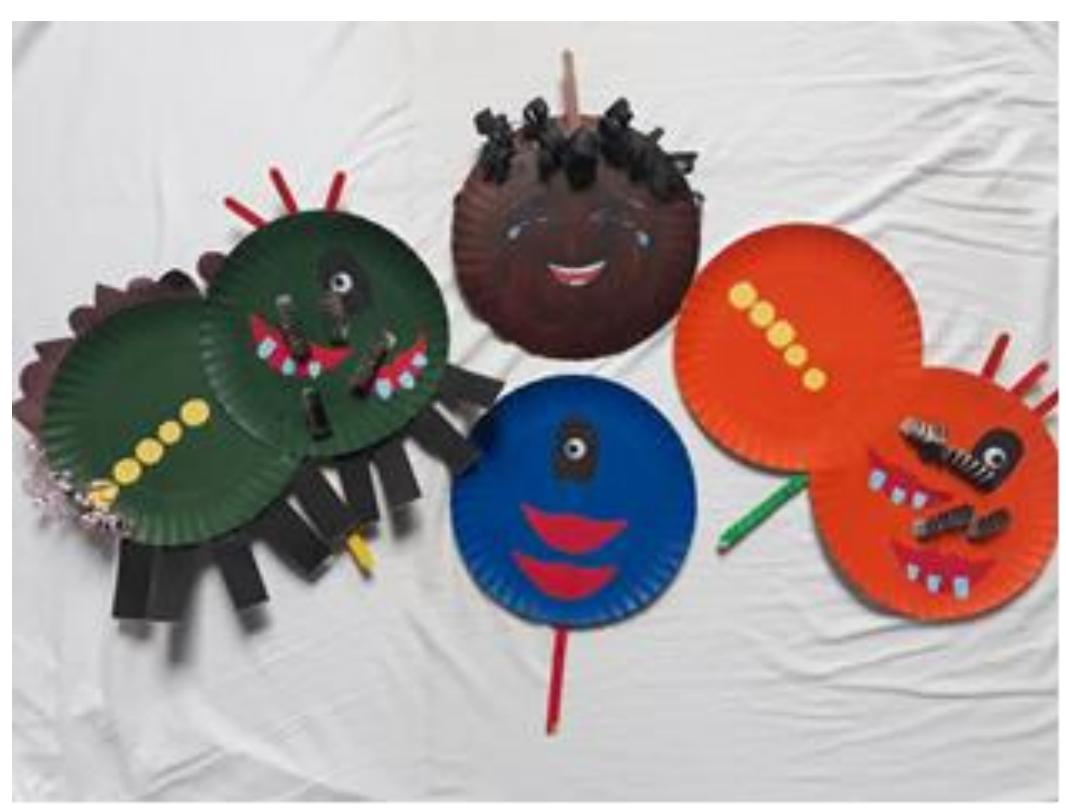

Figura 9: Monstrinhos junto com o personagem Sérgio, confecionados pela professora

Para representar o personagem chamado Sérgio, que no início do livro é um menino assustado e com medo, mas no final acaba achando os monstros engraçados, deixando o medo ir embora, a educadora teve o cuidado de confeccionar dois fantoches do menino com as expressões faciais diferentes, de acordo com os momentos da história. Aproveitando o mesmo prato de papelão, de um lado, vemos o Sérgio assustado, e do outro, o Sérgio sorridente (Figuras 10 e 11):

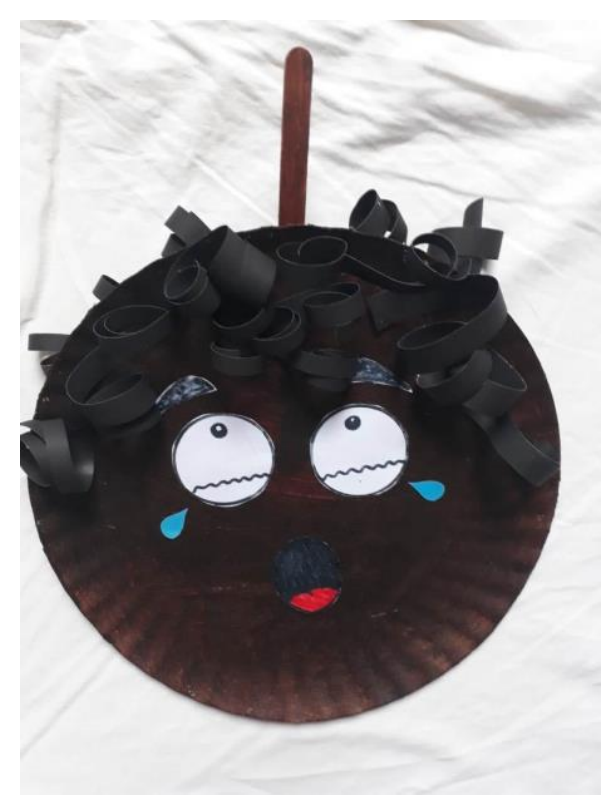

Figura 10: Pesonagem Sérgio assustado 


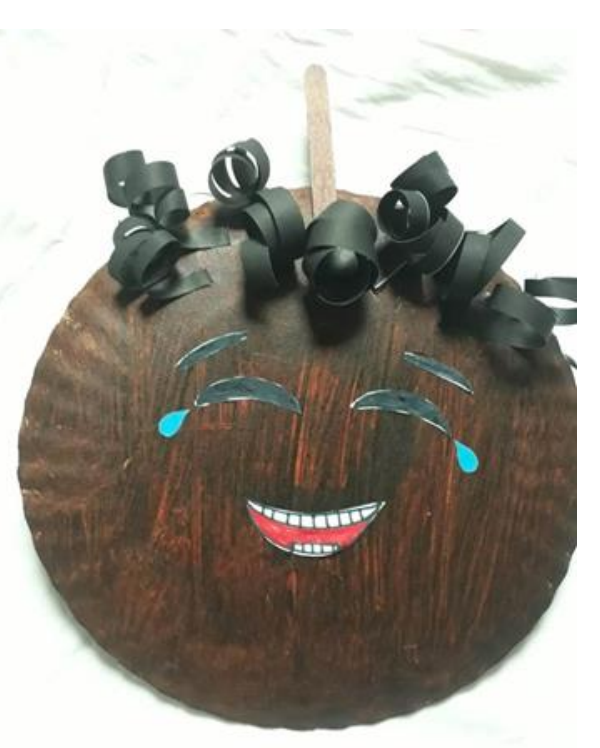

Figura 11: Personagem Sérgio sorrindo

A produção desses artefatos expressa a preocupação da professora em trazer aspectos da narrativa para o contexto dos alunos surdos, através da visualidade dos materiais produzidos. A ideia é que, aos poucos, as crianças façam inferências e percebam que a história em língua de sinais está também no livro, nas ilustrações e no texto verbal escrito em Língua Portuguesa.

Para ampliar ainda mais a identificação das crianças com a história a professora elaborou um vídeo ${ }^{\mathrm{ix}}$ com a Libração da narrativa. A utilização do vídeo de curta-metragem valoriza o visual e possibilita a reprise e uso por vários professores. Lebedeff (2014) considera que vídeos de curta-metragem possibilitam aos alunos uma imersão em práticas sociais de linguagem, considerando-se que estão situados em contextos sócio-histórico culturais, e apresentam interações em Libras em situações reais de comunicação, constituindo-se em OALS - Objeto de Aprendizagem das Línguas. (LEBEDEFF, 2014, p. 1073).

A modalidade do vídeo de curta-metragem tem um tempo curto, de no máximo quinze minutos, porém suficiente para o alcance dos objetivos da atividade de reconto através da libração. Também, segundo a referida autora (p. 1083), “os vídeos são de fácil entendimento $e$ acesso e, possibilitam que a Língua apareça em seu uso comunicativo, pois as histórias simulam situações reais de comunicação".

Procurando perceber a empatia, foram analisados os seguintes pontos na produção do vídeo: em primeiro lugar, a narradora era a própria professora das crianças, além disso, na fase de Pré-produção, foi feito um estudo do contexto da narrativa, do ambiente, dos 
personagens, da confecção dos fantoches, da mensagem passada, do interesse dos espectadores e dos recursos a serem utilizados, além da elaboração dos roteiros literário (organização em sequência dos elementos textuais) e técnico (tais como definição de elementos técnicos e gráficos paras cenas, posição do sinalizante, dos móveis, entre outros) para a gravação do vídeo. Na etapa de Produção, levou-se em consideração a organização do espaço de gravação, o roteiro técnico e os aspectos importantes para um vídeo em Libras de boa qualidade: a luz do ambiente, o enquadramento, o cenário, a distância e a altura da câmera, a posição da professora, o vestuário, a clareza dos sinais. Em seguida, foram gravadas as cenas através de um smartphone. Posteriormente, na etapa de Pós-produção, o curtametragem foi editado em aplicativo de edição de vídeos, quando inseriu-se a legenda em português, o som ambiente foi retirado, feitas as montagens, cortes e ajustes.

Consideramos o vídeo como quarto material analisado. Sobre a produção desse tipo de artefato, trazemos as reflexões de Taveira (2014, p. 247) sobre os principais fins que esse modelo de narrativa cumpre: "1. Aprimorar o uso da língua de sinais; 2. Estimular traduções, adaptações e criações de literatura em Língua de Sinais; 3. Divulgar a língua e os temas próprios à comunidade surda". Outro aspecto relevante é que "o vídeo em Libras continua sendo a principal forma de registro linguístico e, consequentemente, educacional, social e cultural, para os alunos surdos [...]" (ROSADO et all, 2017, p. 199). Por essas justificativas, optamos pela elaboração do vídeo com a Libração da história, ao considerarmos sua importância para os surdos e por expressar a empatia da professora para com os seus alunos, ao planejar cuidadosamente o uso desse recurso e se colocando no lugar de protagonista.

Ainda na proposta para esta história, sugerimos que as crianças sejam convidadas a criarem seus próprios monstrinhos, com pratinhos de papelão, tinta guache e outros materiais disponíveis. Essa prática leva à autoria e à expressão das crianças, cada uma produz um personagem com uma expressão facial diferente, diversidade de cores, que expressam sua visão sobre o texto, bem como sua identidade e sua autoria.

Como quinto material, trazemos a análise de duas produções para o trabalho com a brincadeira cantada Minha boneca de lata: a boneca de lata (Figuras 12 e 13) e um jogo do corpo humano (Figuras 14 e 15). A brincadeira através desta música permite o trabalho com a nomeação e identificação das partes do corpo, coordenação motora ampla e noções de tempo. Junto com a boneca de lata, pode-se utilizar o relógio mostrado anteriormente para explicar o conceito de hora, expresso no trecho da música "levou mais de uma hora pra fazer a arrumação." A professora montou a maior parte da boneca com materiais recicláveis, de fácil acesso, tais como caixas de papelão, rolos de papel higiênico, papel alumínio, fita adesiva, Revista Interinstitucional Artes de Educar. Rio de Janeiro, V. 7, N. 1 - pág. 650-669 janeiroabril de 2021: "Pedagogias Vitais: Corpo, Desejo e Educação" DOI: 10.12957/riae.2021.55349 
papel branco e TNT. Essa confecção autoral permite a participação das crianças, que opinam sobre as cores da roupa da boneca, por exemplo, possibilita o desenvolvimento de habilidades manuais, a expressão criativa e a troca entre os pares. Esses mecanismos promovem a empatia ao refletirem a identidade dos envolvidos e ampliam a comunicação entre os sujeitos.

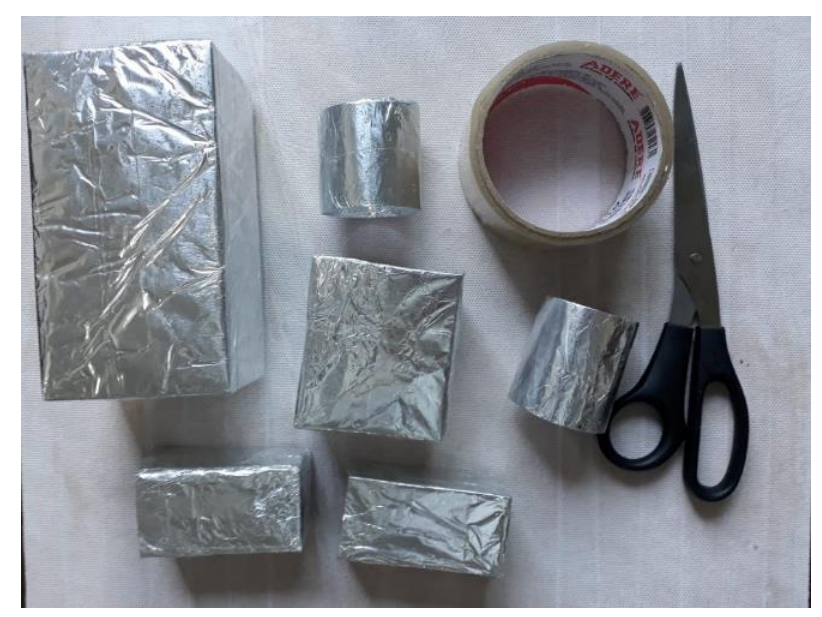

Figura 12: Materiais utilizados

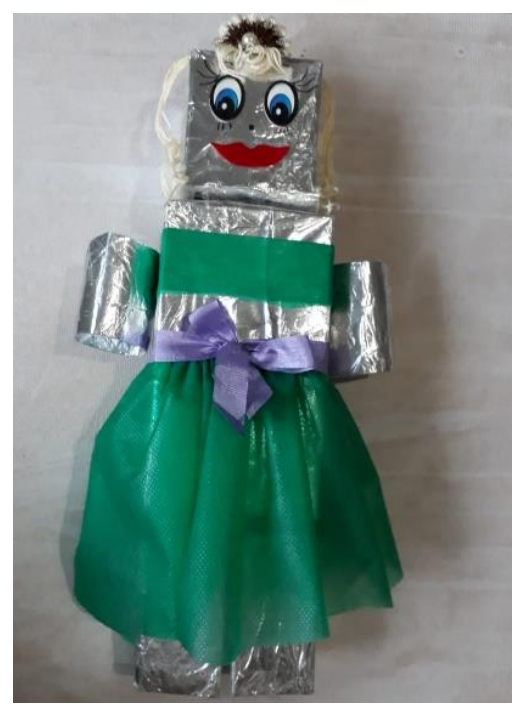

Figura 13: Boneca de leta

No jogo do corpo humano há o desenho de um menino - que no rosto pode ser a foto de um aluno - e vários avatares - que podem ser fotografias do professor ou das crianças realizando os sinas para identificação das partes do corpo para serem coladas sobre os órgãos utilizando o velcro. Essa identificação das crianças com o material didático é importante para a sua aprendizagem, pois gera empatia e prazer em sua execução. Sobre a produção de jogos com fotografias dos alunos e ou professor sinalizando, Taveira (2014) explica que 
é dado destaque à LIBRAS e inserida a língua portuguesa em segundo plano, menor e abaixo do sinal. As placas informativas (ou de sinalização), os calendários, os jogos adaptados são recursos de acessibilidade para pessoa surda e meio de divulgação da língua para que ouvintes passem também a compreendê-la e usá-la. (TAVEIRA, 2014, p. 238)

A autora considera ainda que, ao expor essas produções em sala de aula, elas criam

um ambiente mais seguro e receptivo à comunidade surda ou aos usuários da língua de sinais. Demonstra respeito às línguas que circulam no espaço escolar, principalmente reconhecendo o grupo linguístico minoritário de pessoas surdas na escola. (TAVEIRA, 2014, p. 239)

O respeito é um dos princípios da empatia e, portanto, item importante para esta pesquisa.

Nas fotos dividimos a imagem por questões de tamanho para este artigo, mas o boneco está inteiro no tecido.

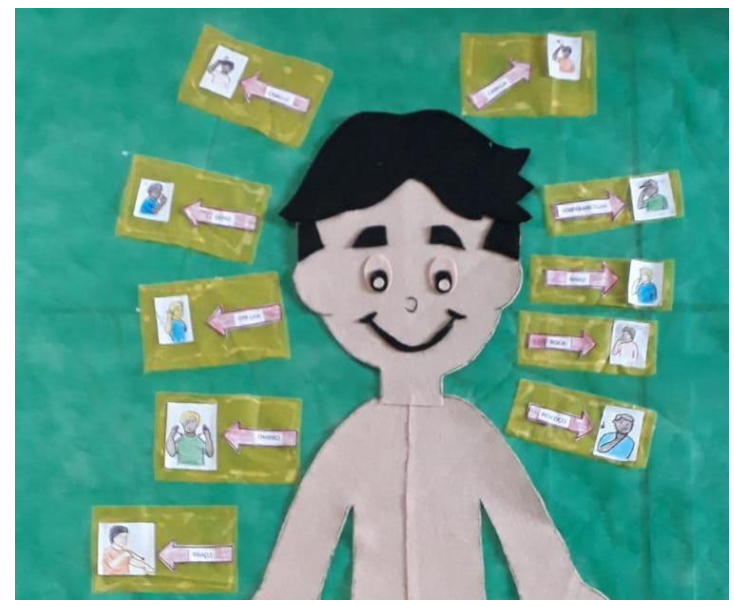

Figura 14: Jogo do corpo humano, parte 1

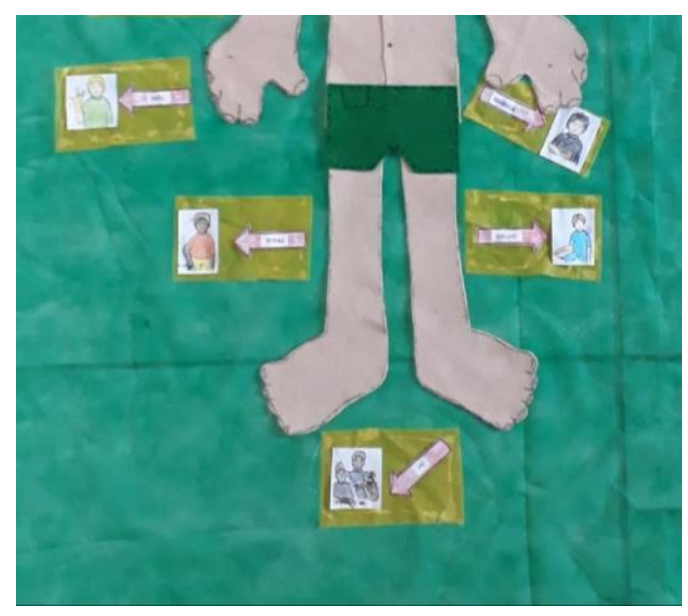

Figura 15: Jogo do corpo humano, parte 2 
Sugerimos também que a silhueta das crianças seja reproduzida em um papel grande a criança deita sobre o papel e o professor risca sua silhueta na folha - para ser produzida como material coletivo. As crianças podem pintar a silhueta, desenhar o rosto, nomear as partes do corpo, sinalizar a nomenclatura, escrever os nomes em parceria com as professoras, de modo a personalizar ainda mais o trabalho.

Por fim, propomos o trabalho com a música As sementes, de Beto Herrmann. A professora sinaliza a letra da música, de modo que as crianças compreendam o seu significado e a sequência dos acontecimentos, expressando-os através de seus corpos. Ao dramatizarem a música, elas se colocam no lugar de sementes, prestes a nascer, transformando-se em árvores. Em seguida uma atividade com elementos naturais (areia, terra, barro, brita, pedras, galhos, conchas) é reproduzida com as crianças. Utilizando uma bacia ou caixa de papelão, a professora distribui porções de areia, barro e outros materiais disponíveis. As crianças ficam livres para confeccionarem suas artes (Figura 16).

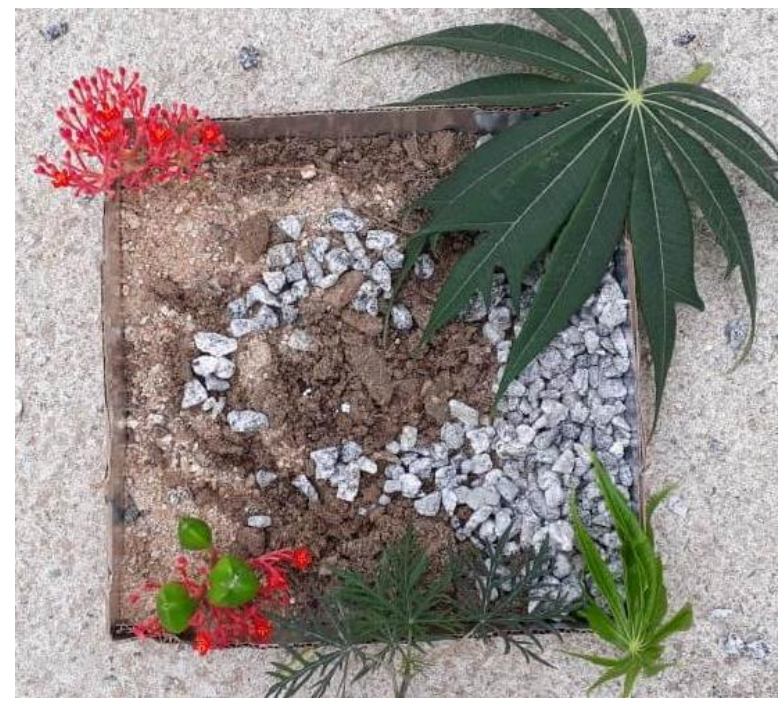

Figura 16: Arte com elementos da natureza

Para o uso de produções musicais do contexto ouvinte com crianças surdas é necessário cuidados como: a tradução correta de modo a seguir a gramática da língua, a expressão facial e corporal que acompanha o enredo e o ritmo musical e o cuidado ao sinalizar e dançar ao mesmo tempo, para que os sinais fiquem claros e o ritmo seja percebido. A música se inclui na variedade de formas de linguagem, que segundo Santaella (2005) engloba também a literatura, o teatro, o desenho, a pintura, a gravura e a escultura. Essas linguagens se materializam através da fotografia, cinema, jornal, rádio e atualmente a internet 
de uma forma geral. Por isso, a importância de trabalhar com esses hibridismos de linguagens (misturas de linguagens de origem visual, verbal, literária) com as crianças surdas, visando proporcionar-lhes experiências empáticas com o contexto que as cerca.

\section{Conclusão}

A concretização de materiais didáticos expressa valores dos autores, traz marcas do professor. O docente, ao produzir seus materiais, assemelha-se ao artesão ou artista, pois expressa nos materiais concepções pedagógicas e de infância, opções estéticas. Os materiais se dirigem às crianças e são pensados para circulação em ambientes escolares. São enunciações que organizam o pensamento, para usar uma expressão bakhtiniana.

A exemplo dos artefatos surdos, os objetos produzidos favorecem a comunicação visual. São materiais produzidos para serem usados em contextos de leituras de livros e brincadeiras poéticas. Funcionam num hibridismo de formas de expressão que se complementam na experiência das crianças. São objetos que pretendem dialogar esteticamente com diferentes linguagens como a literatura, as ilustrações, a língua de sinais, os textos verbais e não verbais. Pressupõem uma criança interativa, curiosa, que produz cultura e que pode participar da confecção, reconhecer a professora e a si como autores.

A palavra e o sinal se colocam no lugar do objeto ou do outro quando se diz de algo na sua ausência, há um jogo do "como se fosse". Os bonecos do tapete são "como se fossem do livro". Os bonecos são "como se fossem" os personagens do livro. No vídeo, é como se fosse a presença da professora. Portanto, esse "como se fosse" presentifica algo na sua ausência, como fenômeno da linguagem. Devido ao fato das referências serem familiares às crianças, a aposta é que haja empatia e que elas se reconheçam e se percebam capazes de fazer seus próprios registros, desenhos e representações. É diferente de se usar um material que já vem pronto, apostilado, com imagens, algumas vezes, muito distantes da realidade imediata da criança. Por isso, a empatia, o colocar-se no lugar do outro, favorece um trabalho com planejamento, materiais e planos individualizados que atendem as peculiaridades das crianças.

Esperamos que ao compartilhar nossas experiências com a produção de materiais e estratégias didáticas, possamos contribuir para a ampliação do debate sobre a educação das crianças surdas. Acreditamos que o currículo da Educação Infantil se constrói na interação com a arte e com a estética. A autoria do professor gera empatia com as crianças que se reconhecem como autoras e sujeitos ativos na construção de conhecimento de si e do mundo. 


\section{REFERÊNCIAS}

BAKHTIN, Mikhail. Marxismo e Filosofia da Linguagem. Trad. de Michel Lahud e Yara Frateschi. 2 ed. São Paulo, Hucitec, 1986.

BORBA, Angela Meyer. Culturas da infância nos espaços-tempos do brincar. 2005. 298f. Tese (Doutorado em Educação) - Programa de Pós-Graduação em Educação, Centro de Estudos Sociais Aplicados, Universidade Federal Fluminense, Niterói, 2005.

BRASIL. Ministério da Educação. Secretaria de Educação Básica. Diretrizes Curriculares Nacionais para a Educação Infantil / Secretaria de Educação Básica. - Brasília: MEC, SEB, 2010. Disponível em: http://portal.mec.gov.br/dmdocuments/diretrizescurriculares 2012.pdf. Acesso em: 10/10/2020.

BRASIL. Base Nacional Comum Curricular. Brasília: MEC, SEB 2017. Disponível em: http://basenacionalcomum.mec.gov.br/images/BNCC EI EF 110518 versaofinal site.pdf.

Acesso em: 10/10/2020.

CAMPELlO, A. R. e S. Pedagogia visual na educação dos surdos-mudos. Tese apresentada ao Programa de Pós-Graduação de Educação da Universidade Federal de Santa Catarina como requisito para a obtenção do título de Doutorado de Educação, 2008, pp 166.

LAGO, Ângela. Coleção Histórias da Onça. Editora Rocco, 2005.

LEBEDEFF, T. B. Alternativas de letramento para crianças surdas: uma discussão sobre o Shared Reading Program. In: REUNIÃO ANUAL DA ANPED, 30., 2007, Caxambu. Anais... Caxambu: ANPED, 2007. p. 1-15. Disponível em: http://30reuniao.anped.org.br/trabalhos/GT15-3727--Int.pdf . Acesso em: 10/10/2020.

LEBEDEFF, B. T. Objetos de aprendizagem para o ensino de línguas: vídeos de curtametragem e o ensino de Libras. RBLA, Belo Horizonte, v. 14, n. 4, p. 1073-1094. 2014. Disponível em: http://dx.doi.org/10.1590/S1984-63982014005000020. Acesso em: 13/10/2020.

MACHADO, A. M. O domador de monstros. Ilustradora: Suppa. São Paulo: FDT, 2003. Coleção conta de novo.

MOURÃO, C. H. N. Literatura Surda: experiências das mãos literárias. Tese de doutorado. Universidade Federal do Rio Grande do Sul. Porto Alegre. 2016. Disponível em: http://www.ufrgs.br/ufrgs/inicial/coringa/repositorio-digital. Acesso em: 15/07/2020.

ROSADO, L. A. da S.; SOUSA, A. de M.; NEJM, V. C. B. A produção de vídeo no contexto da surdez: relato de uma experiência mídia educativa na disciplina TICs do curso bilíngue de pedagogia do INES. In: INES, Revista Espaço. Rio de Janeiro. no 48 juldez . 2017. 
SANTAELLA, Lucia. Matrizes da linguagem e pensamento: sonora visual verbal: aplicações na hipermídia. São Paulo: Iluminuras; FAPESP, 2005.

TAVEIRA, C. Por uma didática da invenção surda: prática pedagógica nas escolaspiloto de educação bilíngue no município do Rio de Janeiro.Tese de doutorado. PUC-RJ. P. 365. 2014.

TAVEIRA, Cristiane Correia; ROSADO, Luiz Alexandre da Silva. O letramento visual como chave de leitura das práticas pedagógicas e da produção de artefatos no campo da surdez. In: LEBEDEFF, Tatiana Bolivar (org.). Letramento visual e surdez. Rio de Janeiro: Walk Editora, 2017. (p. 17 a 47).

\footnotetext{
${ }^{i}$ Mestrado em Educação (PUC-RIO). Doutorado em Educação (UFRJ). Professora adjunta no Departamento de Ensino Superior do Instituto Nacional de Surdos (INES). Professora do Mestrado Profissional em Educação Bilíngue do Programa de Pós-graduação em Educação Bilíngue (PPGEB-INES). Instituto Nacional de Educação de Surdos INES. Rio de Janeiro/RJ - Brasil. ORCID iD https://orcid.org/0000-0001-8154-3207

${ }^{i i}$ Licenciatura plena em Pedagogia (UNIRIO). Pós-graduada em Tutoria em Educação a Distância e Docência do Ensino Superior (FUTURA-SP). Mestranda do Programa de Pós-graduação em Educação Bilíngue do Instituto Nacional de Educação de Surdos (PPGEB-INES). Instituto Nacional de Educação de Surdos INES. Rio de Janeiro/RJ - Brasil. ORCID iD https://orcid.org/0000-0001-8811-9599

iii Ver: https://www.fnde.gov.br/index.php/programas/programas-do-livro/consultas/editais-programaslivro/item/13526-edital-pnld-2022

iv Ver: https://www.in.gov.br/en/web/dou/-/decreto-n-10.502-de-30-de-setembro-de-2020-280529948

${ }^{v}$ Fundo das Nações Unidas para a Infância.

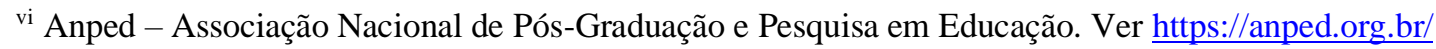

vii Ver: https://www3.gallaudet.edu/clerc-center/our-resources/shared-reading-project.html

viii Ver: https://www.gallaudet.edu/

${ }^{\text {ix }}$ Assista ao vídeo através do link: https://youtu.be/iHdqODDIDV4
} 